\title{
Capturing the social relevance of government transparency and accountability using a behavioral lens
}

\section{Gregory A. Porumbescu ${ }^{*}$, Marcia Grimes ${ }^{\dagger}$, Stephan Grimmelikhuijsen $^{\ddagger}$}

\begin{abstract}
The link between transparency and accountability is an often discussed feature of good governance. Despite a great deal of attention, this relationship remains poorly understood. We argue that the adoption of a behavioral lens to evaluate the impact of transparency on accountability offers new opportunities to discover novel mechanisms that contribute to a more systematic understanding of when and why increasing government transparency enhances accountability. Shedding light on such mechanisms not only promises to improve existing theory, but to also render transparency more meaningful to the applied world. To make this argument, we highlight findings from four articles that form the basis of this symposium issue and discuss avenues for further research.
\end{abstract}

Tn June 2020, the United States was beset with widespread protests following the death of George Floyd at 1 the hands of the Minneapolis Police Department. As the protests rapidly grew, police were deployed. Not long after, reports emerged of police officers reporting for duty without badges, covering up their badge numbers (Graff, 2020), and detaining journalists dispatched to cover the protests (Tracy \& Abrams, 2020). These attempts to withhold information from the public were noteworthy given that a main point of the protests was to call for greater police accountability.

The efforts on the part of some police officers to withhold information from the public raised broader questions over the effectiveness of efforts to enhance the transparency of police work. Would the police officers have behaved differently had they not covered up their badge numbers or the journalists were not detained? More substantively, just how much do efforts to increase transparency really matter to accountability?

Questions such as these lay the foundation for this symposium issue, which seeks to build upon our understanding of the relationship between transparency and accountability by examining it from a behavioral perspective. At present, most work in this area takes an institutional perspective, focusing on how factors such as political competition (Berliner, 2014) or economic conditions (e.g., Albornoz, Esteban, \& Vanin, 2014) foster greater transparency, or how institutional features such as culture (Grimmelikhuijsen et al., 2013) or the presence of mass media outlets condition the effects of transparency on outcomes such as trust in government or corruption.

With the exception of voting behavior, the literature has paid much less attention to the micro-level, behavioral perspective on transparency and accountability. This gap in attention is problematic. For instance, while institutions contributed to police transparency through the use of badge numbers by the police and the presence of a free press, decisions to try and subvert transparency and eschew accountability were made by

\footnotetext{
$*$ Rutgers University-Newark and Yonsei University

† University of Gothenburg

¥ Utrecht University

Address correspondence to Gregory Porumbescu at (greg.porumbescu@rutgers.edu)

Copyright: (C) 2021. The authors license this article under the terms of the Creative Commons Attribution 4.0

International License.
} 
individuals. This shows that micro-level (individual) behavior can affect the impact of transparency on accountability.

Transparency and accountability are distinct but interrelated concepts. Where transparency is often defined in terms of information disclosure (e.g. Grimmelikhuijsen \& Meijer, 2014), accountability also entails processing and responding to that information (Bovens, 2007). Transparency is thought to enable participation and debate in some form, which when successful results in a strengthening of accountability (Porumbescu \& Grimmelikhuijsen, 2018; Bauhr \& Grimes, 2017; Hood, 2010). While there are institutional analyses of what makes for effective accountability (Bovens, Schillemans \& ' $t$ Hart, 2008), the role of individual human behavior in translating government transparency into government accountability in public administration is often overlooked (Aleksovska, Schillemans \& Grimmelikhuijsen, 2020).

This symposium seeks to bridge the gap between these lines of inquiry by encouraging investigations of the individual behavioral responses presupposed to link transparency to accountability. While theory prescribes ways in which the public should respond to government information in order for government transparency to enhance accountability, do users of government information respond as expected? Addressing this question through a behavioral lens is challenging because it requires researchers to move beyond establishing effects and focus on identifying mechanisms that are difficult to identify and empirically examine. As a result, extant theory provides insight into what transparency can do, but provides little insight as to when and why.

\section{The Need for Greater Attention to Mechanisms in Transparency Research}

Development economists offer crucial advances regarding the effects of transparency on accountability - and by extension government performance - in the context of developing countries. Field experiments compare important social outcomes across treated and non-treated communities. Treatments consist of, for example, arranging a series of meetings facilitated by local NGOs in Uganda, where information about local service providers benchmarked against government standards was presented, followed by inclusive discussion of needed improvements (Björkman \& Svensson, 2009). A second landmark study arranged a newspaper campaign, also in Uganda, publicizing revenue flows in a large education grant program to enable citizen monitoring to detect leakage (Reinikka \& Svensson, 2005). Both of these influential studies showed significant effects on infant mortality and birth weight, as well as educational attainment. Subsequent work has pointed to the fact that neither study examined citizens' behavioral responses, leaving open the question of whether local communities in fact utilized the information and demanded accountability, or simply changed their own behavior in ways that effected better results (Raffler, Posner, \& Parkerson, 2018; Grandvoinnet, Aslam, \& Raha, 2015).

Subsequent studies have sought to replicate these early efforts and simultaneously to empirically map the behavioral responses theorized to mediate the transparency-accountability link. Using a set-up similar to that of Björkman and Svensson (2009), Raffler et al. (2018) examine the effects of comprehensive information and participation interventions on residents using 376 health centers in Uganda. Unlike Björkman and Svensson, however, the intervention generated no effect whatsoever on infant mortality and birth weight, and only moderate effects on patient satisfaction and treatment quality. A yet more ambitious attempt to capture the microlevel mechanisms at work comes from the Transparency for Development (T4D) project in 400 communities in Indonesia and Tanzania, with interventions in 100 communities in each country (Arkedis, Creighton, Dixit, Fung, Kosack, \& Levy, 2019). In addition to monitoring impacts on child health outcomes, the study also assesses effects on civic engagement and empowerment, two factors very often presumed to arise subsequent to the provision of relevant information, and to promote better public service provision.

The similarly ambitious field experimental project Metaketa I has disseminated information about corruption among politicians in seven countries, and monitored results of subsequent elections to ascertain whether better information enhances electoral accountability (Dunning, Grossman, Humphreys, Hyde, McIntosh, \& Nellis, 2019). Both of these research projects yielded resoundingly null results; T4D finds no effects on health outcomes, and only very moderate effects on civil participation and empowerment (Arkedis et al., 2019), and the Metaketa I interventions do not change voting behavior in any of the studied countries to a significant degree.

Studies such as the T4D and Metaketa represent some of the most important assessments of the link between transparency and accountability to date. They also highlight a lack of understanding of the processes 
through which information interventions affect change. For example, the studies we have discussed all consider citizens' or communities' responses to information, but many other types of actors may also participate in accountability efforts, such as government officials, journalists, civil society, and business representatives. Thus, despite replicating similar findings across a number of contexts, why this information did or did not trigger accountability remains unclear.

Second, much of the important quantitative assessments of the effect of transparency on accountability focus on developing countries, where accountability deficits are undeniably large, but accountability efforts are also comparatively difficult. Redressing abuses or even poor performance in government is difficult in any setting, but certainly much more so where even higher order government institutions may be corrupt and perform poorly (Fox, 2015; Grandvoinnet et al., 2015; Mansuri \& Rao, 2013).

Thus, in addition to factors that mediate the relationship between transparency and accountability, there is also a need to understand how institutional context conditions behavior. The institutional environment in which the transparency and accountability initiatives are embedded constitutes perhaps the most important set of contextual conditions. The perceived impartiality, effectiveness, and responsiveness of government institutions and agencies can affect behavioral responses to transparency in numerous ways, including the extent to which citizens and other accountability actors feel their actions may credibly prompt an effective response, as well as their beliefs about their own ability and right to effect change, i.e., both their external and internal efficacy.

This symposium on government transparency and accountability aims to provide a first glance into potential mediating and moderating factors in the transparency and accountability relation. This symposium presents four contributions to our knowledge on micro-level conditions.

\section{Introducing the Contributions in this Symposium}

Table 1 summarizes the key findings presented by the articles in the symposium. The articles provide key insights into the mediating and moderating factors that affect transparency and accountability behaviors.

Table 1. Overview of Articles in this Symposium

\begin{tabular}{|c|c|c|c|}
\hline Authors & Method & Key finding & Plausible Mechanism \\
\hline $\begin{array}{l}\text { Guardino and Mettler } \\
(2020)\end{array}$ & $\begin{array}{l}\text { Survey experiment with } 526 \\
\text { participants }\end{array}$ & $\begin{array}{l}\text { Providing information } \\
\text { shifts policy support to align } \\
\text { with immediate material in- } \\
\text { terest. }\end{array}$ & $\begin{array}{l}\text { Relevant policy information } \\
\text { updates policy preferences } \\
\text { and may strengthen ac- } \\
\text { countability. }\end{array}$ \\
\hline $\begin{array}{l}\text { Ingrams, Kaufman and } \\
\text { Jacobs }(2020)\end{array}$ & $\begin{array}{l}\text { Survey experiment with } 465 \\
\text { participants }\end{array}$ & $\begin{array}{l}\text { Providing information } \\
\text { about decision procedure } \\
\text { leads to higher satisfaction, } \\
\text { fairness, and trust. }\end{array}$ & $\begin{array}{l}\text { Transparency can increase } \\
\text { trust, but might come at the } \\
\text { expense of greater participa- } \\
\text { tion. }\end{array}$ \\
\hline $\begin{array}{l}\text { Jenkins, Landgrave and } \\
\text { Martinez (2020) }\end{array}$ & $\begin{array}{l}\text { Field experiment sending } \\
\text { FOI requests to municipali- } \\
\text { ties in the five most popu- } \\
\text { lated US states. }\end{array}$ & $\begin{array}{l}\text { FOIA increases transpar- } \\
\text { ency and potentially ac- } \\
\text { countability. Requester } \\
\text { identity does not affect gov- } \\
\text { ernment response. }\end{array}$ & $\begin{array}{l}\text { Regulatory context - the } \\
\text { presence of an enforceable } \\
\text { FOIA - helps to strengthen } \\
\text { the link between transpar- } \\
\text { ency and accountability. }\end{array}$ \\
\hline $\begin{array}{l}\text { Damgaard and Nielsen } \\
(2020)\end{array}$ & $\begin{array}{l}\text { Survey experiment in the } \\
\text { field, offering true perfor- } \\
\text { mance data to service users } \\
(1,185 \text { parents from } 15 \\
\text { schools) }\end{array}$ & $\begin{array}{l}\text { Information is available } \\
\text { with only minor effects on } \\
\text { subsequent voice and exit } \\
\text { behavior. }\end{array}$ & $\begin{array}{l}\text { Only information about low } \\
\text { performance prompted ac- } \\
\text { countability response } \\
\text { (voice). }\end{array}$ \\
\hline
\end{tabular}


Insights into Mediating Factors.

One mediating set of factors in the transparency-accountability link is individuals' attitudinal responses. For transparency to lead to accountability-oriented responses, we first need an attitudinal shift. Two articles in the symposium investigate the effects of transparency on citizen attitudes. First, Guardino and Mettler (2020) find that providing policy-specific information led subjects to align their preferences with their immediate material interests. More specifically, if they learn that tax expenditures mostly benefit higher-income people, lower- and middle-income people become less supportive of these policies. They argue that "greater informational outreach regarding complicated and arcane tax expenditures could bolster public accountability for government actions that favor economically narrow and privileged segments of the population" (Guardino \& Mettler, 2020:1). Here we see that policy-specific transparency can prompt citizens to update their policy preferences so that they better reflect their own material interest. Based on this study, transparency has the potential to amplify accountability at the micro-level.

Secondly, Ingrams, Kaufman, and Jacobs (2020) carry out a survey experiment that indirectly links transparency and participation to good governance outcomes such as perceived fairness and trust. The findings show that highlighting elements of transparency and participation in a fictious municipal decision-making process increases perceived fairness and satisfaction. Based on these outcomes we could argue that transparency leads to more positive attitudes and - arguably - less accountability-related behavior.

One important contextual difference is that the Guarino and Mettler study experimentally manipulates actual transparency into tax expenditures, whereas Ingrams et al. examine stated transparency and decisionmaking, providing only limited detail about the information itself. Hence, one potentially important factor in the transparency-accountability link may be related to the specificity of transparency itself.

Insights into Moderating Factors.

The two other articles in this symposium provide insights into the contextual factors that moderate the transparency-accountability relation. First, using a field experiment, Jenkins, Landgrave, and Martinez (2020) investigate whether FOIA requests lead to faster and more useful responses by the government than regular requests. They indeed find that this is the case and - interestingly - that FOIA requests from political donors are not replied to more frequently or faster than non-donor requesters. Overall, this shows that the regulatory context - the presence of an enforceable FOI Act - helps to improve transparency.

Secondly, Damgaard and Nielsen (2020) conduct a survey experiment in the field, offering true performance data to service users. This is a novel contribution to existing performance data studies because experiments using performance information are generally based on hypothetical scenarios. Damgaard and Nielsen employ a sample of parents with children in public schools and investigate whether exposure to performance data affects accountability behaviors (voice and exit behavior). Interestingly, they consistently find little evidence "that performance information affects user satisfaction, intended voice and exit behaviors, incumbency voting, or goal prioritization" (Damgaard \& Nielsen, 2020:1). Hence, this is a clear case in which transparency of performance data does not lead to accountability behaviors. The authors explain that their findings, when considered along those from other work (i.e., Holbein \& Hassell, 2019), may suggest that the effects of performance information are contingent upon the clarity of the performance information and how good a job it does in conveying consequences.

\section{A Research Agenda for a Behavioral Lens on Transparency and Accountability}

The four studies that form the basis for this symposium make important contributions to strengthening our understanding of when and why transparency may impact accountability. Previous work has shown the utility of a behavioral lens on accountability (Raffler et al., 2018; Schillemans, 2016) or transparency separately (Porumbescu, Lindeman, Ceka, \& Cucciniello, 2017), yet this symposium highlights the utility of a behavioral lens to deepen our theoretical knowledge of the complex relationship between transparency and accountability. Building upon these findings, we close the introduction to this symposium issue on transparency and accountability with recommendations for future research. 


\section{Factors Mediating the Transparency-Accountability Relationship}

Theories of change related to transparency to a great extent predict that information will allow or prompt citizens to take some form of accountability-related action. Yet explanations of this relationship are frequently poorly formulated and subject to little empirical investigation. To build a more generalizable theory on transparency, research must develop a more robust understanding of behavioral mechanisms that help to translate transparency into accountability across different settings. Investigating the attitudinal predecessors - change in preferences or intention to act - can enable such research that examines the implications of transparency for accountability, while controlling for the organizational and contextual heterogeneity in natural settings. We therefore suggest that future research might look into effects on the updating of preferences of citizens, internal efficacy, government performance, and finally on the effects on actors other than citizens.

One category of attitudinal responses relates to the updating of preferences. As Guardino \& Mettler (2020) show, information on the redistributive effects of social programs prompts changes in respondents' preferences in a way that seems to better reflect their own interests. Building on this, a subsequent issue is to understand how updating citizen preferences and expectations links to behavior and internal efficacy. Namely, two questions emerge. First, how much of an impact on citizen preferences does transparency have to have before it prompts action? In other words, because accountability often follows crises, just how bad do things have to get before members of the public decide to invest their time and energy into calling government to account?

Second, while citizens may be more inclined to act out when they feel there is an issue of significant consequence, there is likely a tipping point in terms of internal efficacy at which they feel that things have diverged so far from personal preferences that they are unable to change things. This point dovetails with implications from Ingrams et al. (2020) in that, while citizens are unlikely to engage in accountability behaviors when they trust government, it also appears likely that citizens will not engage in accountability behaviors when they deeply distrust government.

Taken together, if transparency affects citizens' expectations of government performance as well as their perception of themselves as principals, this may overall enhance accountability in a political system. That said, Ingrams et al. (2020) show that transparency signals may positively affect citizens' trust in government bodies and political processes, and may thus instead allay suspicions and citizens' inclinations to ask nasty questions. Exploring these mediating responses on the individual level warrant continued attention moving forward.

Transparency is also expected to induce better government performance by enhancing motivation among agency heads and within organizations to improve performance and efficiency preemptively. There is hardly any empirical research addressing this important mechanism. Here too, the behavioral and organizational responses may be highly heterogeneous and specific to the context, but examining behavioral intentions may provide a means to determine behavioral responses across a range of sectors and settings. Do managers express an awareness of increased openness and possible scrutiny, and does this awareness trigger intentions to take measures to increase efficiency, capacity or responsiveness, or even to make budget reallocations? Transparency initiatives in most cases increase the visibility of specific aspects of an organizations' operations. Just as with the development of performance indicators themselves, the publication of performance indicators or increasing transparency in one area of an organization's operations may be at the expense of other aspects or areas of performance.

Finally, the behavioral lens can be applied to actors other than citizens. Most citizens may not actually have the time or willingness to read government information and may only have a slight awareness of the existence of transparency mechanisms (Grimmelikhuijsen, Piotrowski \& Van Ryzin, 2020). 'Infomediaries', such as non-state actors such as the media and civil society are often seen as crucial linking pins between information use and accountability (Dewachter, Holvoet, Kuppens, \& Molenaers, 2018). Previous research suggests that government transparency seems to better allow civil society to engage in accountability to mitigate corruption (Bauhr \& Grimes, 2014), but both media and civil society may also engage to further a range of ends related to government performance. Ascertaining whether transparency indeed enhances the involvement of these types of actors may also prove a fruitful line of inquiry.

\section{Factors Moderating the Transparency-Accountability Relationship}

Research on transparency has by now elucidated that information can have positive, negative, or no effects whatsoever depending on both the nature of the information, the opportunities for accountability actions, and 
the prospective users of the information (Cucciniello et al., 2017; Kosack \& Fung, 2014). Exit is a viable response where feasible alternatives exist and the cost of changing service providers do not exceed expected gains. Citizens are unlikely to voice criticism and report problems if grievance redress mechanisms require effort or are simply lacking, or if information is presented in ways that are not accessible to the target audience. Adding to these types of insights, we see room for continued attention to four contextual (moderating) conditions under which transparency may amplify accountability: the social context, political polarization, the regulatory context, and the nature of the institutional context.

A first avenue for future research is to investigate the social context as a moderating condition. One such condition relates to the fact that many forms of citizen engagement present coordination challenges. While single complaints may effect change, broader and more sustained efforts to demand answers and express grievances are more likely to do so. Transparency together with opportunities for citizens to identify other users, and in particular users who share the same concerns, would, we hypothesize, plausibly increase the impact of transparency itself. Other approaches might be to involve users in determining what types of information or performance indicators they would like access to, an approach that in one study seemed to strengthen participants' commitments and thus enable sustained monitoring efforts (Barr, Mugisha, Serneels, \& Zeitlin, 2012). The existence of social capital in a setting may also increase the likelihood of coordinated involvement in response to transparency initiatives. Where well-functioning user groups, such as parent-teacher associations, are in place, information is more likely to prompt discussion and possibly also pressure for improvements where shortfalls become apparent.

Secondly, political polarization may affect the willingness to use information to hold it to account. We know already that citizens' capacity to avail themselves and act upon information initiatives - largely a function of education - may amplify the effect of transparency on accountability (e.g., Lindstedt \& Naurin, 2010). However, an issue of great concern relates not to citizens' ability to grasp policy relevant information, but their willingness to do so. As citizens' trust in government and even information issued by governments wane, and so called 'knowledge resistance' seems to spread throughout even established democracies (Klintman, 2019), we may expect the effects of transparency initiatives to change as well. Political polarization may imply that partisan sympathies determine how target audiences receive and either act on or abstain from acting on information. Sympathizers of incumbent parties may tolerate reports of performance failures if they feel those reports may have been issued with malicious intent, and therefore not represent the truth.

Third, the regulatory context is a likely factor influencing the behavior of government officials (Ingrams, 2017). Though it does not speak specifically to this point, Jenkins et al. (2020) find that requests to government that invoke FOIA laws prompt more expedient responses than requests that do not invoke a FOIA law, suggesting that such regulations do not necessarily enhance the overall responsiveness of government offices. Examining whether specific regulatory requirements or settings affect government officials' responses can be investigated further. For instance, transparency measures perhaps even incentivize public sector managers and employees to shift their attention to more easily observable operations - and away from less observable operations - issues that merit continued attention in research (e.g., Van Thiel \& Leeuw, 2002).

Finally, the nature of the institutional context may also moderate the extent to which transparency strengthens accountability. Initiatives to increase transparency have emerged in a wide range of countries and institutional conditions vary considerably among them. The findings on transparency initiatives in developing countries have to date been underwhelming. These null findings may reflect the difficulty of prompting citizens as voters or service users to assume an active role in holding government accountable when they otherwise have little opportunity or prior experience doing so. Counter to theoretical prediction, however, Damgaard and Nielsen (2020) also find only limited effects of transparency initiatives on accountability behaviors in Denmark. Research along these lines, carried out in different settings and with explicit attention to whether effects vary depending on the nature of the institutional characteristics, will continue to shed needed light on the generality of these findings and the kinds of institutional conditions under which transparency may or may not trigger the hoped for responses. 


\section{An Agenda to Understand the Societal Relevance of Transparency}

Investigating mediating and moderating factors that shape the effect of transparency on accountability are not just needed to satisfy our intellectual curiosity, but also to ensure that transparency reforms have a substantive and constructive social impact. In the opening example, we highlighted efforts made by some police officers to eschew transparency and avoid accountability. While this example highlights troubles of realizing theory in practice, it also speaks to the power of transparency. Stemming from press coverage and efforts on the part of concerned residents, coverage of the protests did prompt widespread and high-level discussions about police reform.

It is just that transparency theories offer little insight into the mechanisms responsible for translating transparency in the case of protests into questions of police reform. In order for transparency, not just of police, but of any government organization to have broader social relevance, understanding such mechanisms is essential. Building on the insights of past work and the novel contributions of the four studies that form the basis for this symposium, we argue that developing a better understanding of behavioral mechanisms in particular, will play a crucial role in strengthening the social relevance of transparency reforms.

\section{References}

Albornoz, F., Esteban, J., \& Vanin, P. (2014). Market distortions and government transparency. Journal of the European Economic Association, 12(1), 200-222.

Aleksovska, M., Schillemans, T., and S. Grimmelikhuijsen. (2020). Lessons from five decades of experimental and behavioral research on accountability: A systematic literature review. Journal of Behavioral Public Administration, 2(2).

Arkedis, J., Creighton, J., Dixit, A., Fung, A., Kosack, S., \& Levy, D. (2019). Can transparency and accountability programs improve health? Experimental evidence from Indonesia and Tanzania. Harvard Kennedy School Faculty Research Working Paper Series.

Barr, A., F. Mugisha, P. Serneels, and A. Zeitlin. (2012). "Information and collective action in the community monitoring of schools: Field and lab experimental evidence from Uganda." Unpublished manuscript.

Bauhr, M., \& Grimes, M. (2014). Indignation or resignation: The implications of transparency for societal accountability. Governance, 27(2), 291-320.

Bauhr, M., \& Grimes, M. (2017). Transparency to curb corruption? Concepts, measures and empirical merit. Crime, Law and Social Change, 68(4), 431-458.

Berliner, D. (2014). The political origins of transparency. The Journal of Politics, 76(2), 479-491.

Björkman, M., \& Svensson, J. (2009). Power to the people: Evidence from a randomized field experiment on community-based monitoring in Uganda. The Quarterly Journal of Economics, 124(2), 735-769.

Bovens, M. (2007). Analysing and assessing accountability: A conceptual framework 1. European Law Journal, 13(4), 447-468.

Bovens, M., Schillemans, T., and P. 't Hart. (2008). Does public accountability work? An assessment tool. Public Administration 86(1): 225-242.

Damgaard, P. R., \& Nielsen, P. A. (2020). Does performance disclosure affect user satisfaction, voice, and exit? Experimental evidence from service users. Journal of Behavioral Public Administration, 3(2).

Dewachter, S., Holvoet, N., Kuppens, M., \& Molenaers, N. (2018). Beyond the short versus long accountability route dichotomy: Using multi-track accountability pathways to study performance of rural water services in Uganda. World Development, 102, 158-169.

Dunning, T., G. Grossman, M. Humphreys, S. D. Hyde, C. McIntosh, and G. Nellis. (2019). Information, accountability, and cumulative learning: Lessons from metaketa I: Cambridge University Press.

Fox, J. A. (2015). "Social accountability: What does the evidence really say?" World Development 72:346-361.

Graff, G. M. (2020, June 9). Badge-less police officers are showing up at protests. And it's dangerous. Washington Post. Retrieved from https://www.washingtonpost.com/opinions/2020/06/09/dangerousrise-anonymous-cops/

Grandvoinnet, H., Aslam, G., \& Raha, S. (2015). Opening the black box: The contextual drivers of social accountability. The World Bank.

Grimmelikhuijsen, S. G., \& Meijer, A. J. (2014). Effects of transparency on the perceived trustworthiness of a government organization: Evidence from an online experiment. Journal of Public Administration Research and Theory, 24(1), 137-157.

Grimmelikhuijsen, S. G., Piotrowski, S. J., \& Van Ryzin, G. G. (2020). Latent transparency and trust in government: Unexpected findings from two survey experiments. Government Information Quarterly, 37(4), 101497.

Grimmelikhuijsen, S., Porumbescu, G., Hong, B., \& Im, T. (2013). The effect of transparency on trust in government: A cross-national comparative experiment. Public administration review, 73(4), 575-586.

Guardino, M., \& Mettler, S. (2020). Revealing the "Hidden welfare state": How policy information influences 
public attitudes about tax expenditures. Journal of Behavioral Public Administration, 3(1).

Holbein, J. B., \& Hassell, H. J. (2019). When your group fails: The effect of race-based performance signals on citizen voice and exit. Journal of Public Administration Research and Theory, 29(2), 268-286.

Hood, C. (2010). Accountability and transparency: Siamese twins, matching parts, awkward couple?. West European Politics, 33(5), 989-1009.

Ingrams, A. (2017). The legal-normative conditions of police transparency: A configurational approach to open data adoption using qualitative comparative analysis. Public Administration, 95(2): 527-545.

Ingrams, A., Kaufmann, W., \& Jacobs, D. (2020). Testing the open government recipe: Are vision and voice good governance ingredients?. Journal of Behavioral Public Administration, 3(1).

Jenkins, N. R., Landgrave, M., \& Martinez, G. E. (2020). Do political donors have greater access to government officials? Evidence from a FOIA field experiment with US municipalities. Journal of Behavioral Public Administration, 3(2).

Klintman, M. (2019). Knowledge resistance: How we avoid insight from others. Manchester University Press.

Kosack, S., and A. Fung. (2014). "Does transparency improve governance?" Annual Review of Political Science17:65-87.

Lindstedt, C., \& Naurin, D. (2010). Transparency is not enough: Making transparency effective in reducing corruption. International Political Science Review, 31(3), 301-322.
Mansuri, G., \& Rao, V. (2013). Localizing development: Does participation work?. Washington, DC: World Bank.

Porumbescu, G.A., and S. Grimmelikhuijsen. (2018). Linking decision-making procedures to decision acceptance and citizen voice: Evidence from two studies. The American Review of Public Administration 48(8), 902-914.

Porumbescu, G. A., Lindeman, M. I., Ceka, E., \& Cuccini ello, M. (2017). Can transparency foster more understanding and compliant citizens?. Public Administra tion Review, 77(6), 840-850.

Raffler, P., Posner, D. N., \& Parkerson, D. (2018). The weakness of bottom-up accountability: Experimental evidence from the Ugandan health sector. Unpublished manuscript.

Reinikka, R., \& Svensson, J. (2005). Fighting corruption to improve schooling: Evidence from a newspaper campaign in Uganda. Journal of the European Economic Association, 3(2-3), 259-267.

Schillemans, T. (2016). Calibrating public sector accountability: Translating experimental findings to public sector accountability. Public Management Review, 18(9), 1400-1420.

Tracy, M. and R. Abrams. (2020). Police target journalists as Trump Blames 'Lamestream Media' for protests. New York Times. Retrieved from https://www.nytimes.com/2020/06/01/business/media/reportersprotests-george-floyd.html

Van Thiel, S., \& Leeuw, F. L. (2002). The performance paradox in the public sector. Public Performance \& Management Review, 25(3), 267-281. 